\title{
Decreased Chronic Widespread Pain on Nonworking Days Might Help Differentiate Work-Related Musculoskeletal Disorders From Fibromyalgia: A Cross-Sectional Study of Working Females
}

\author{
Mehmet Akif GÜLER'ㄹ, Mehmet Onat ÇAKIT²] \\ ${ }^{1}$ Department of Physical Medicine and Rehabilitation, Gaziosmanpaşa Taksim Training and Research Hospital, Istanbul, Turkey \\ ${ }^{2}$ Department of Family Medicine, Ankara Training and Research Hospital, Health Sciences University, Ankara, Turkey
}

\begin{abstract}
Objectives: This study aims to investigate whether fibromyalgia (FM) and work-related musculoskeletal disorders can be differentiated in working females by comparing their pain on nonworking and working days.

Patients and methods: The study included 142 female workers (mean age 30.0 \pm 6.5 years; range, 18 to 50 years) from five different work areas: 27 factory workers, 27 janitors, 25 data automation employees, 31 nurses, and 32 physiotherapists. Demographic characteristics were recorded. FM was diagnosed according to 2016 criteria of the American College of Rheumatology. The extended version of the Nordic Musculoskeletal Questionnaire was used to evaluate the participants' musculoskeletal complaints and the severity of their pain. Pain was assessed with visual analog scale (VAS) scores on working and nonworking days. Differences in the participants' VAS-Pain on working and nonworking days were compared. Sensitivity, specificity, receiver operating characteristic (ROC) curve and area under the curve (AUC) were used.

Results: Of the 142 working females, 32 (22.5\%) were diagnosed with FM. There was a significant difference in nonworking day VAS-Pain scores between the FM patients and the work-related musculoskeletal disorder patients $(p<0.001)$. Analysis of ROC curve for VAS-Pain difference scores yielded AUC of $0.860(95 \%$ confidence interval $=0.774-0.945)(p<0.001)$. ROC analysis identified 1.5 centimeters of VAS-Pain difference score as the cut-point for differentiating work-related musculoskeletal disorders and FM resulting in sensitivity of $97 \%$ and specificity of $96 \%$. FM patients had significantly higher rates of positive answers to "visit health professionals," "take medication," and "sick leave" questions compared to patients with work-related musculoskeletal disorders $(p<0.001)$.

Conclusion: The amount of the decrease in pain on nonworking days may help differentiate work-related musculoskeletal disorders from FM in working females. Therefore, evaluating pain on nonworking days may help clinicians diagnose and treat FM correctly.

Keywords: Fibromyalgia, musculoskeletal diseases, widespread chronic pain, work, working females.
\end{abstract}

Fibromyalgia (FM) is a chronic disease characterized by widespread pain (WSP), depression, anxiety, cognitive impairment, stiffness, fatigue, and sleep disorders. ${ }^{1}$ According to revised 2016 criteria from the American College of Rheumatology (ACR), WSP, necessarily pain in four out of five body regions, is needed to diagnose FM. ${ }^{2}$ Another system for diagnosing FM evaluates WSP in nine body regions. ${ }^{3}$
Usually, if no alternative cause can be identified for WSP, FM is the term used for widespread musculoskeletal pain. ${ }^{4}$ However, there is no standard definition of WSP, and the prevalence of various musculoskeletal conditions that cause WSP ranges from 11.4 to $24 \% .^{5}$

One of the main causes of WSP is work-related disease. ${ }^{6-9}$ The term work-related musculoskeletal

Received: June 27, 2019 Accepted: November 14, 2019 Published online: February 07, 2020

Correspondence: Mehmet Akif Güler, MD. Gaziosmanpaşa Taksim Eğitim ve Araştırma Hastanesi Fiziksel Tıp ve Rehabilitasyon Kliniği, 34255 Gaziosmanpaşa, İstanbul, Türkiye. Tel: +90 212 - 9453000 e-mail: makifguler89@gmail.com

Güler MA, Çakıt MO. Decreased Chronic Widespread Pain on Nonworking Days Might Help Differentiate Work-Related Musculoskeletal Disorders From Fibromyalgia: A Cross-Sectional Study of Working Females. Arch Rheumatol 2020;35(4):486-494. 
disorders covers diseases caused or aggravated by work that are characterized by discomfort, impairment, disability, or persistent pain in muscles, bones, tendons, cartilage, and other soft tissue, with or without physical manifestation. ${ }^{10}$ Lower back pain, neck pain, and other musculoskeletal pain are the leading causes of years lived with disability and result in substantial economic loss to both individuals and the community. ${ }^{11,12}$ Several studies have found evidence of a relationship between physical exertion (repetitive motion, excessive force, sustained posture, and prolonged sitting/standing) at work and work-related musculoskeletal disorders. ${ }^{13,14}$

The frequency of musculoskeletal disorders is higher in females than in males, mainly because of differences in body size, muscle strength, oxygen intake, hormones, and tolerance for pain. FM can cause disability, the need to take sick leave, and reduced work capacity in the workplace. Females diagnosed with FM have greater psychosocial stress and poorer rates of return to work, and the severity of symptoms influences the ability of FM patients to work. ${ }^{15,16}$ To properly diagnose females with and treat them for WSP, it is crucial to differentiate WSP caused by work-related musculoskeletal disorders from FM.

To our knowledge, no study has evaluated how to differentiate the WSP of work-related musculoskeletal disorders from FM. Therefore, in this study, we aimed to investigate whether FM and work-related musculoskeletal disorders can be differentiated in working females by comparing their pain on nonworking and working days.

\section{PATIENTS AND METHODS}

This study was conducted at Ankara Training and Research Hospital between May 2018 and October 2018. The study included 142 female workers (mean age 30.0 \pm 6.5 years; range, 18 to 50 years) from five different work areas: 27 factory workers, 27 janitors, 25 data automation employees, 31 nurses, and 32 physiotherapists. The female factory workers were recruited from a dynamite factory in Çankırı, and all other workers were recruited from various hospitals in Ankara and Istanbul. The study protocol was approved by the Ankara Training and Research Hospital Ethics Committee
(\#30-01042018-03). A written informed consent was obtained from each participant. The study was conducted in accordance with the principles of the Declaration of Helsinki. This trial was registered with the ClinicalTrials.gov database, NCT03535454.

The study enrolled females employed at their current workplace for at least three months and who reported pain in at least one body region in the past 12 months. Exclusion criteria were any chronic illness (hypertension, diabetes mellitus, thyroid disease, vitamin insufficiency, etc.); chronic use of any medication; alcohol or drug abuse; pregnancy; rheumatic disease (rheumatoid arthritis, ankylosing spondylitis, etc.); or any infectious-metabolic, neurologic, or psychiatric disease. Information on participants' medical background was obtained from them verbally. Data from pre-employment medical check-ups, including complete blood count, respiratory function tests, audiometric examination, and chest X-ray, were evaluated for all participants, and patients were excluded from the study when abnormalities were present. Workers diagnosed with and treated for FM before the study were also excluded.

The age, weight, height, comorbidities, medication usage, and working hours of each participant were recorded. The level of pain, evaluated using a visual analog scale (VAS), was recorded for working and nonworking days. First, pain on working days was evaluated by asking each participant to mark a $10 \mathrm{~cm}$ line in response to the question "How bad is your pain on a scale from 0 to 10 on working days, where 0 means no pain and 10 means the worst pain possible?" Next, pain on nonworking days was evaluated by asking each participant to mark a $10 \mathrm{~cm}$ line in response to the question "How bad is your pain on a scale from 0 to 10 on nonworking days, where 0 means no pain and 10 means the worst pain ever?" VAS-Pain(difference) scores were calculated as VAS-Pain(working days) - VAS-Pain(nonworking days). A negative VAS-Pain(difference) score indicates an increase in pain on nonworking days, and a positive value indicates a decrease in pain.

The extended version of the Nordic Musculoskeletal Questionnaire (NMQ-E) was administered to all participants (Figure 1). This questionnaire has two sections for evaluating the musculoskeletal system, particularly in 


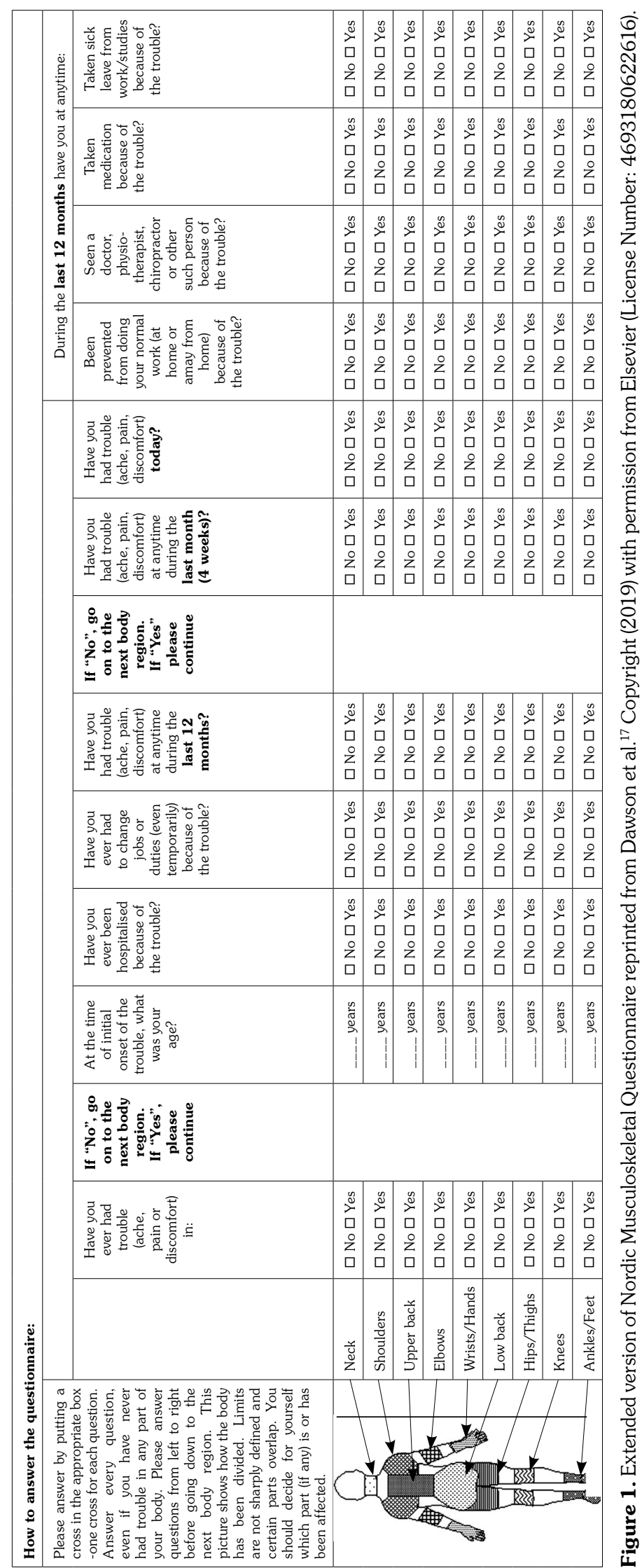


occupational diseases. One section identifies the location of pain by inquiring about symptoms at nine sites-the neck, upper back, lower back, shoulders, elbows, wrists/hands, hips/thighs, knees, and ankles/feet-and determines when the pain first started. The participants were also asked to report (i) whether they had experienced any pain ever in their lives, during the past 12 months, during the past month, or on the day the questionnaire was administered; (ii) whether their work was affected by pain; and (iii) whether they needed to use any medication, undergo treatment, or take any sick leave because of the intensity of the pain. With the exception of the age question, all questions were dichotomous. ${ }^{17}$ The validity and reliability of the NMQ-E for use in Turkish populations were established in 2019.18

The revised 2016 ACR FM diagnostic criteria were used to diagnose FM in the participants. These criteria consist of two parts. In the first part, the patient is asked to mark areas of pain in the following 19 different body areas in five regions: (i) jaw (left), shoulder girdle (left), upper arm (left), and lower arm (left) in the upper left region; (ii) jaw (right), shoulder girdle (right), upper arm (right), and lower arm (right) in the upper right region; (iii) hip (left), upper leg (left), and lower leg (left) in the lower left region; (iv) hip (right), upper leg (right), and lower leg (right) in the lower right region; and $(v)$ neck, upper back, lower back, chest, and abdomen in the axial region. The WSP index (WPI) is calculated as the number of painful areas. In the revised criteria, a patient must have pain in at least four of the five regions to be diagnosed with FM. In the second part, the severity of fatigue, waking unrefreshed, and cognitive symptoms are scored from 0 to 3 over the past seven days, and headache, abdominal cramps, and depression in the past six months are rated to calculate a symptom severity scale (SSS) score. FM is diagnosed if WPI $\geq 7$ and SSS $\geq 5$ or if $\mathrm{WPI}=4-6$ and $\mathrm{SSS} \geq 9$. The fibromyalgia severity scale (FSS; also known as the polysymptomatic distress scale) is calculated as the sum of the WPI and SSS scores. ${ }^{2}$

Sample size was calculated using the MedCalc statistical software (version 19.0.1, Ostend, Belgium), before recruitment of the participants. If $\alpha$ was taken 0.05 and (1- $\alpha)$ was taken 0.95 and area under receiver operating characteristic

Table 1. Demographic and clinical features of female workers

\begin{tabular}{|c|c|c|c|c|c|c|c|}
\hline & \multicolumn{3}{|c|}{ Group $1(n=32)$} & \multicolumn{3}{|c|}{ Group $2(n=110)$} & \multirow[b]{2}{*}{$p$} \\
\hline & $\mathrm{n}$ & $\%$ & Mean \pm SD & $\mathrm{n}$ & $\%$ & Mean \pm SD & \\
\hline Age (year) & & & $30.4 \pm 6.1$ & & & $29.9 \pm 6.7$ & 0.72 \\
\hline Weight (kg) & & & $60.9 \pm 1.6$ & & & $64.5 \pm 10.7$ & 0.08 \\
\hline Height $(\mathrm{cm})$ & & & $161.3 \pm 6.8$ & & & $161.2 \pm 5.9$ & 0.89 \\
\hline Body mass index $\left(\mathrm{kg} / \mathrm{m}^{2}\right)$ & & & $23.6 \pm 3.8$ & & & $24.9 \pm 4.7$ & 0.13 \\
\hline \multicolumn{8}{|l|}{ Education } \\
\hline No education & 0 & 0 & & 2 & 1.8 & & \multirow{4}{*}{0.24} \\
\hline Primary-Middle School & 6 & 18.8 & & 8 & 7.3 & & \\
\hline High School & 9 & 28.1 & & 35 & 31.8 & & \\
\hline University & 17 & 53.1 & & 65 & 59.1 & & \\
\hline \multicolumn{8}{|l|}{ Marital status } \\
\hline Married & 23 & 71.9 & & 76 & 69.1 & & \multirow{3}{*}{0.91} \\
\hline Single & 5 & 15.6 & & 17 & 15.5 & & \\
\hline Other* & 4 & 12.5 & & 17 & 15.5 & & \\
\hline Daily working (hour) & & & $9.3 \pm 1.5$ & & & $9.1 \pm 1.4$ & 0.69 \\
\hline Job experiences (year) & & & $6.5 \pm 4.3$ & & & $6.3 \pm 4.6$ & 0.81 \\
\hline VAS-pain (working days) (cm) & & & $5.3 \pm 1.3$ & & & $5.1 \pm 1.6$ & 0.41 \\
\hline VAS-pain (non-working days) (cm) & & & $4.9 \pm 1.6$ & & & $2.4 \pm 1.3$ & $<0.001$ \\
\hline
\end{tabular}


(ROC) curve was calculated as 0.70 , expected total sample size was calculated as 140 participants.

\section{Statistical analysis}

For statistical analysis, IBM SPSS version 20.0 software (IBM Corp., Armonk, NY, USA) was used. The mean and standard deviation for continuous variables and percentage for categorical variables were calculated. The homogeneity of the distribution was determined by Kolmogorov-Smirnov test. The Chi-square (or Fisher's exact) test was used to compare categorical data. Two groups were compared using the independent t-test or Mann-Whitney $\mathrm{U}$ test. The Spearman correlation test was performed for correlation analysis and $p<0.05$ was accepted as statistically significant.

A ROC curve analysis was used to determine the sensitivity and specificity of VAS-Pain(difference) scores in differentiating between FM and workrelated musculoskeletal disorders.

\section{RESULTS}

Table 1 shows the demographic characteristics of the participants. A total of 150 participants were included at the beginning of the study. Eight were excluded because of additional conditions (restless leg syndrome, rheumatoid arthritis, alcohol use, and pregnancy in one patient each and medication use and depression in two patients each). The participants were divided

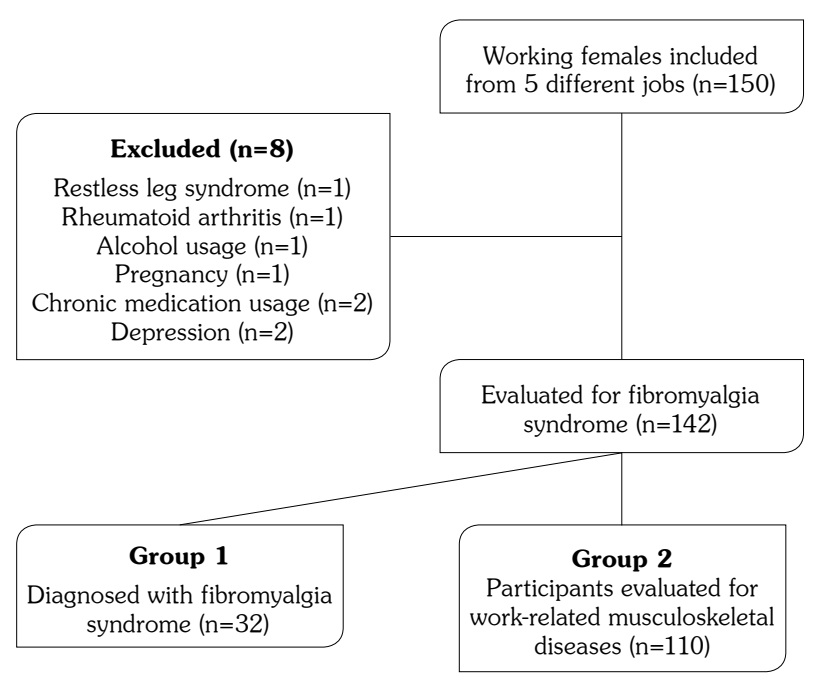

Figure 2. Flowchart of study. into two groups according to their FM diagnosis. Group 1 included patients diagnosed with FM ( $\mathrm{n}=32 ; 22.5 \%$ ), and group 2 included non-FM patients ( $n=110 ; 77.5 \%$; Figure 2). There were no statistical differences between the groups in terms of participants' demographic characteristics (p>0.05).

The VAS-Pain(working days) scores of the two groups did not differ significantly $(p=0.410)$, but there was a significant difference between the groups in VAS-Pain(nonworking days) scores $(p<0.001)$. ROC analyses revealed that VAS-Pain(difference) $>1.5 \mathrm{~cm}$ had a sensitivity of $97 \%$ and specificity of $96 \%$ for differentiating work-related musculoskeletal disorders from FM in working females (area under the curve $[\mathrm{AUC}]=0.860 ; 95 \%$ confidence interval [CI]: 0.774-0.945; $p<0.001$; Figure 3). This means that if a patient suffering from chronic WSP had a VAS-Pain(nonworking days) score that was more than 1.5 points lower than the VAS-Pain(working days) score, there was a strong probability that patient was suffering from work-related musculoskeletal disorders rather than FM. Based on this result, five of the patients in group 1 (15.6\% of all FM patients) in this study would be diagnosed with work-related musculoskeletal disorders rather than FM.

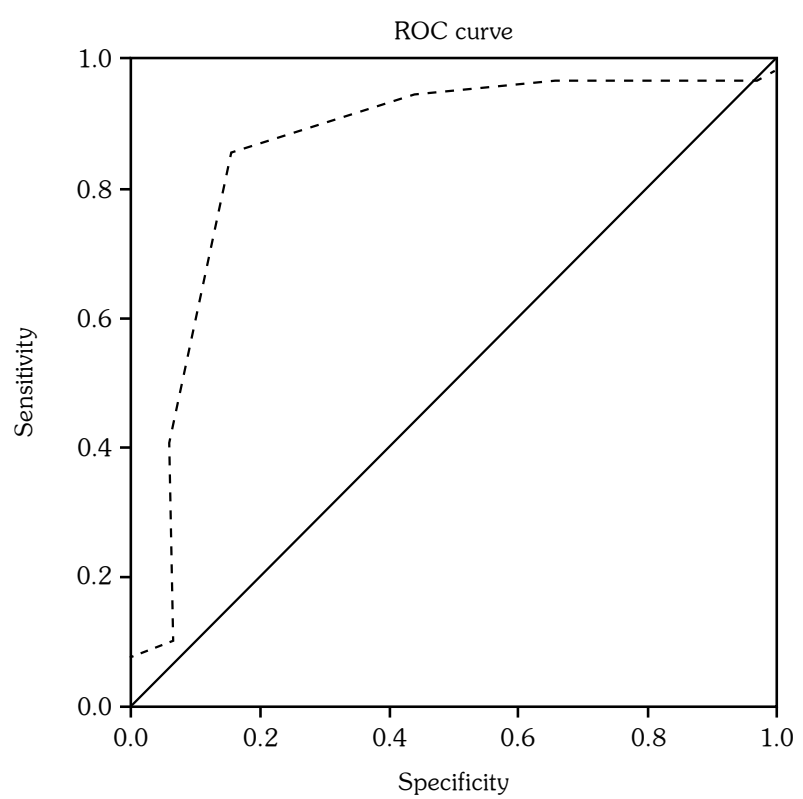

Figure 3. Receiver operating characteristic curve of visual analog scale-pain difference.

ROC: Receiver operating characteristic. 
Table 2. Comparison of extended version of Nordic Musculoskeletal Questionnaire scores of groups

\begin{tabular}{|c|c|c|c|c|c|c|c|}
\hline & \multicolumn{3}{|c|}{ Group $1(\mathrm{n}=32)$} & \multicolumn{3}{|c|}{ Group $2(n=110)$} & \multirow[b]{2}{*}{$p$} \\
\hline & $\mathrm{n}$ & $\%$ & Mean \pm SD & $\mathrm{n}$ & $\%$ & Mean \pm SD & \\
\hline \multicolumn{8}{|l|}{ NMQ-E (total body regions) (0-9 points) } \\
\hline Lifetime prevalence & & & $6.2 \pm 1.4$ & & & $3.0 \pm 1.7$ & $<0.001$ \\
\hline Annual prevalence (last 12 months) & & & $6.0 \pm 1.5$ & & & $2.2 \pm 1.3$ & $<0.001$ \\
\hline Month prevalence (last month) & & & $5.3 \pm 1.3$ & & & $1.8 \pm 1.2$ & $<0.001$ \\
\hline Point prevalence (today) & & & $4.9 \pm 1.5$ & & & $1.6 \pm 1.1$ & $<0.001$ \\
\hline \multicolumn{8}{|l|}{ NMQ-E (yes) } \\
\hline Prevention of normal work & 15 & 46.9 & & 36 & 32.7 & & 0.14 \\
\hline Visit to health professional & 11 & 34.4 & & 15 & 13.6 & & 0.008 \\
\hline Taken medication & 15 & 46.9 & & 26 & 23.6 & & 0.01 \\
\hline Sick leave & 12 & 37.5 & & 15 & 13.6 & & 0.002 \\
\hline
\end{tabular}

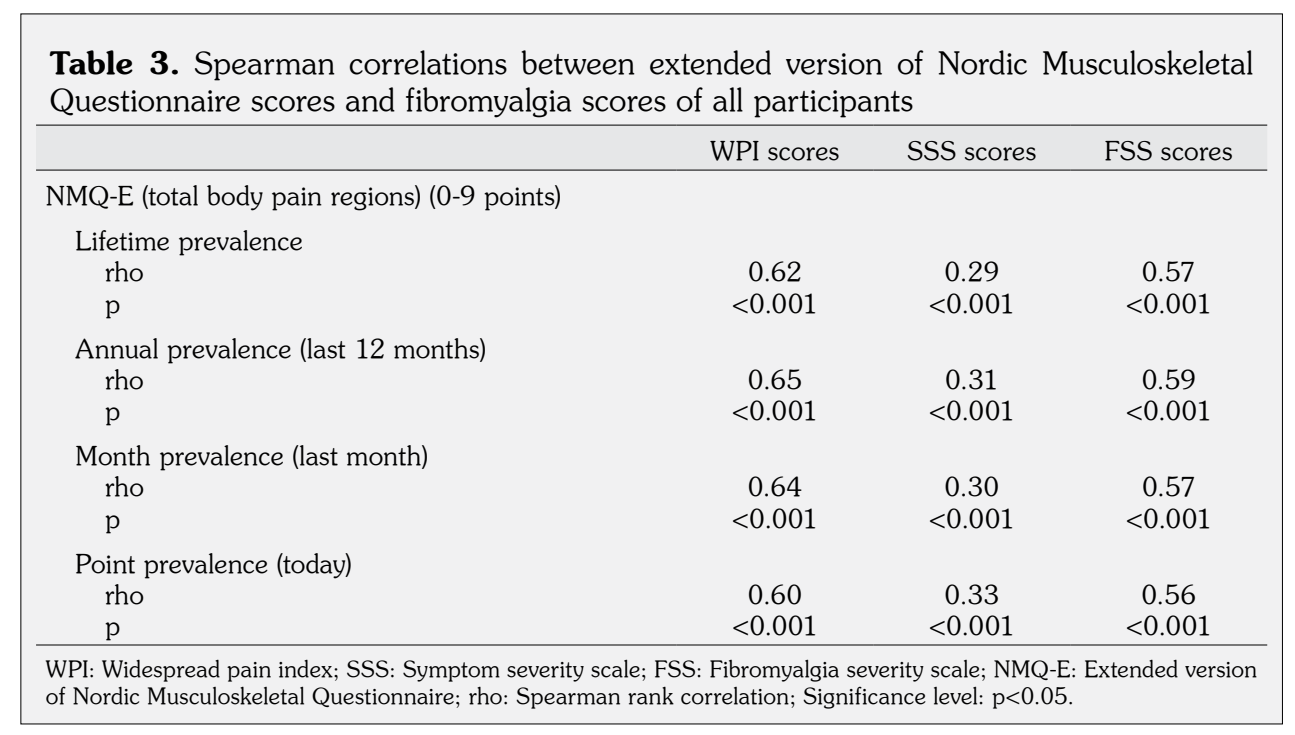

Responses to the NMQ-E indicated that the total affected body regions differed significantly between the two groups for all of the time durations (present day, past month, 12 months, and lifetime prevalence; $\mathrm{p}<0.001)$. There was also a significant difference between the groups in terms of answering "yes" to the questions "visit a health professional" ( $\mathrm{p}=0.008)$, "take medication" ( $\mathrm{p}=0.011)$, and "used sick leave" ( $\mathrm{p}=0.002$; Table 2$)$.

There was a significant strong correlation between WPI scores and NMQ-E total affected body regions for all of the time durations $(\mathrm{p}<0.001)$. There were also significant medium to strong correlations between SSS and FSS scores and NMQ-E total affected body regions of the participants $(\mathrm{p}<0.001$; Table 3$)$.

\section{DISCUSSION}

Fibromyalgia is a chronic disease that affects many people, particularly females, worldwide. In the modern era, diseases that affect females are becoming more important because they can affect females' performance in the labor force. ${ }^{19}$ The main complaint of FM patients is chronic WSP, but 
other diseases may also cause WSP. ${ }^{4}$ Work-related musculoskeletal disorders are a primary cause of multisite musculoskeletal pain. ${ }^{8,9,20,21}$ Multisite musculoskeletal pain is another term that can be used instead of WSP to diagnose FM. ${ }^{22}$

Gerdle et al. ${ }^{23}$ identified a high prevalence of WSP, particularly in females, which could negatively affect work status. However, their study did not mention whether WSP was caused by FM or work-related musculoskeletal disorders. To diagnose WSP, Gerdle et al. ${ }^{23}$ used a drawing that divided the body into 10 different anatomical regions. Similarly, we used the NMQ-E, which divides the body into nine different regions to diagnose work-related pain, and we evaluated WSP using 2016 criteria, which address 19 parts in five regions of the body. ${ }^{2,14} \mathrm{We}$ found a significant correlation between NMQ-E scores and WPI. However, according to our results, these diagnostic criteria were inadequate for determining whether workers' pain was connected to FM or work-related musculoskeletal disorders. This may be because of the widespread prevalence of musculoskeletal pain in both conditions with overlapping symptoms, including feeling fatigued, waking unrefreshed, and having problems sleeping, which makes it difficult to make a definitive diagnosis. For example, Abdul Rahman et al. $^{24}$ evaluated work fatigue in 201 nurses and showed that chronic, persistent fatigue was present in $30.3 \%$ of the participants. Kecklund et $a .^{25}$ studied the effects of waking early on the quality of sleep and whether sleep was refreshing. They concluded that unrefreshed sleep is associated with early work schedules. We did not evaluate participants' sleep quality or fatigue. Future research should focus on patients' sleep and fatigue and how they affect WSP during nonworking days.

Differentiating between work-related musculoskeletal disorders and FM is left to the clinician. This study shows that, in this process, evaluating whether a patient's pain persists on nonworking days might be of assistance, because FM pain is experienced continuously and is not relieved when the patient is on leave. According to the National Health Interview Survey, three quarters of those reporting a clinical diagnosis of FM do not reach levels of pain severity necessary and sufficient for a diagnosis. ${ }^{26}$ Therefore, the use of FM criteria in clinical practice may be insufficient and may result in the overdiagnosis or misdiagnosis of FM. ${ }^{27}$ If the recent FM diagnostic criteria were revised or reevaluated, one question that should be considered for diagnostic purposes is whether patients have decreased pain on nonworking days. This study is the first to show that the amount of pain on nonworking days may be of value for differentiating work-related musculoskeletal disorders from FM.

The rate of employment of patients with FM varies geographically, ranging from 34 to $77 \%$ in various studies. ${ }^{19}$ FM patients are often affected by pain all day long, and their capacity to perform daily activities is reduced. ${ }^{28}$ In one study, cognitive profiles were affected by various diseases, including FM and chronic fatigue syndrome. ${ }^{29} \mathrm{FM}$ can cause sleep disturbances, fatigue, cognitive dysfunction, and emotional distress. ${ }^{30}$ Females diagnosed with FM reported that they were negatively affected by the disease, in that other workers interpreted their situation as "being lazy" and it was difficult for them to remain employed. ${ }^{31}$ Collado et al. ${ }^{32}$ showed that FM has a considerable negative impact on patients' families and employment due to loss of the ability to work. A study conducted in 2014 found that FM patients received more Social Security Disability services than healthy individuals but less services than individuals with other rheumatic diseases (osteoarthritis and rheumatoid arthritis. ${ }^{33}$ Reisine et al. ${ }^{34}$ explored the differences between employed and unemployed females with FM and reported better results for the former group in terms of pain, fatigue, stiffness, depression, disease-specific health status, and physical aspects of quality of life. However, both groups were equally impaired in physical capacity, and that study showed that a diagnosis of FM is important for work performance, disability, and loss of work time in the workplace. ${ }^{34}$ For all of these reasons, proper diagnosis and treatment of FM or workrelated musculoskeletal disorders are critical.

We examined whether the decrease in pain on nonworking days could be used to differentiate chronic WSP caused by workrelated musculoskeletal disorders from FM in working females. In this study, $22.5 \%$ of female workers were originally diagnosed with FM. However, after evaluating the participants' pain on nonworking days, we concluded that $15.6 \%$ of these FM patients should be excluded from 
the FM group and treated as having work-related musculoskeletal disorders.

One limitation of this study is that it included only working females. Future studies should investigate the relationship between work-related musculoskeletal disorders and FM in a larger sample that includes males. Moreover, we did not evaluate the working hours of the participants; some of the participants worked night shifts, while the pain of the participants was evaluated separately on working and nonworking days.

In conclusion, differentiating work-related musculoskeletal disorders from FM, particularly in working females, may be difficult for clinicians in daily practice because of an overlap in symptoms. This study confirmed that evaluating a patient's decrease in WSP on nonworking days can help clinicians to resolve this difficulty. A decrease in VAS-Pain of more than 1.5 points on nonworking days has a high sensitivity and specificity for differentiating work-related musculoskeletal disorders from FM. Further studies with larger study populations that also evaluate patients' sleep and fatigue may expand understanding of this topic.

\section{Declaration of conflicting interests}

The authors declared no conflicts of interest with respect to the authorship and/or publication of this article.

\section{Funding}

The authors received no financial support for the research and/or authorship of this article.

\section{REFERENCES}

1. Clauw DJ, D’Arcy Y, Gebke K, Semel D, Pauer L, Jones KD. Normalizing fibromyalgia as a chronic illness. Postgrad Med 2018;130:9-18.

2. Wolfe F, Clauw DJ, Fitzcharles MA, Goldenberg DL, Häuser W, Katz RL, et al. 2016 Revisions to the 2010/2011 fibromyalgia diagnostic criteria. Semin Arthritis Rheum 2016;46:319-29.

3. Arnold LM, Bennett RM, Crofford LJ, Dean LE, Clauw DJ, Goldenberg DL, et al. AAPT Diagnostic Criteria for Fibromyalgia. J Pain 2019;20:611-28.

4. Sluka KA, Clauw DJ. Neurobiology of fibromyalgia and chronic widespread pain. Neuroscience 2016;338:114-29.

5. Butler S, Landmark T, Glette M, Borchgrevink $\mathrm{P}$, Woodhouse A. Chronic widespread pain-the need for a standard definition. Pain 2016;157:541-3.

6. de Cássia Pereira Fernandes R, Pataro SM, de Carvalho RB, Burdorf A. Erratum to: The concurrence of musculoskeletal pain and associated work-related factors: a cross sectional study. BMC Public Health 2016;16:1131.

7. Cimmino MA, Ferrone C, Cutolo M. Epidemiology of chronic musculoskeletal pain. Best Pract Res Clin Rheumatol 2011;25:173-83.

8. Neupane S, Nygård $\mathrm{CH}$, Oakman J. Work-related determinants of multi-site musculoskeletal pain among employees in the health care sector. Work 2016;54:689-97.

9. Straube S. Work and multisite musculoskeletal pain. Pain 2014;155:847-8.

10. Aptel M, Aublet-Cuvelier A, Cnockaert JC. Workrelated musculoskeletal disorders of the upper limb. Joint Bone Spine 2002;69:546-55.

11. Vos T, Flaxman AD, Naghavi M, Lozano R, Michaud C, Ezzati M, et al. Years lived with disability (YLDs) for 1160 sequelae of 289 diseases and injuries 1990-2010: a systematic analysis for the Global Burden of Disease Study 2010. Lancet 2012;380:2163-96.

12. Milhem M, Kalichman L, Ezra D, Alperovitch-Najenson D. Work-related musculoskeletal disorders among physical therapists: A comprehensive narrative review. Int J Occup Med Environ Health 2016;29:735-47.

13. da Costa BR, Vieira ER. Risk factors for workrelated musculoskeletal disorders: A systematic review of recent longitudinal studies. Am $\mathrm{J}$ Ind Med 2010;53:285-323.

14. Yao Y, Zhao S, An Z, Wang S, Li H, Lu $\mathrm{L}$, et al. The associations of work style and physical exercise with the risk of work-related musculoskeletal disorders in nurses. Int $\mathrm{J}$ Occup Med Environ Health 2019;32:15-24.

15. Howard KJ, Mayer TG, Neblett R, Perez Y, Cohen $\mathrm{H}$, Gatchel RJ. Fibromyalgia syndrome in chronic disabling occupational musculoskeletal disorders: prevalence, risk factors, and posttreatment outcomes. J Occup Environ Med 2010;52:1186-91.

16. Palstam A, Mannerkorpi K. Work Ability in Fibromyalgia: An Update in the 21st Century. Curr Rheumatol Rev 2017;13:180-7.

17. Dawson AP, Steele EJ, Hodges PW, Stewart S. Development and test-retest reliability of an extended version of the Nordic Musculoskeletal Questionnaire (NMQ-E): a screening instrument for musculoskeletal pain. J Pain 2009;10:517-26.

18. Alaca N, Safran EE, Karamanlargil Aİ, Timucin E. Translation and cross-cultural adaptation of the extended version of the Nordic musculoskeletal questionnaire into Turkish. J Musculoskelet Neuronal Interact 2019;19:1-10.

19. Henriksson CM, Liedberg GM, Gerdle B. Women with fibromyalgia: work and rehabilitation. Disabil Rehabil 2005;27:685-94. 
20. Hanvold TN, Lunde LK, Koch M, Wæersted M, Veiersted KB. Multisite musculoskeletal pain among young technical school students entering working life. BMC Musculoskelet Disord 2016;17:82.

21. Eckhoff C, Straume B, Kvernmo S. Multisite musculoskeletal pain in adolescence as a predictor of medical and social welfare benefits in young adulthood: The Norwegian Arctic Adolescent Health Cohort Study. Eur J Pain 2017;21:1697-706.

22. Dean LE, Arnold L, Crofford L, Bennett R, Goldenberg D, Fitzcharles MA, et al. Impact of Moving From a Widespread to Multisite Pain Definition on Other Fibromyalgia Symptoms. Arthritis Care Res (Hoboken) 2017;69:1878-86.

23. Gerdle B, Björk J, Cöster L, Henriksson K, Henriksson $\mathrm{C}$, Bengtsson A. Prevalence of widespread pain and associations with work status: a population study. BMC Musculoskelet Disord 2008;9:102.

24. Abdul Rahman H, Abdul-Mumin K, Naing L. Psychosocial work stressors, work fatigue, and musculoskeletal disorders: comparison between emergency and critical care nurses in Brunei Public Hospitals. Asian Nurs Res (Korean Soc Nurs Sci) 2017;11:13-18.

25. Kecklund G, Akerstedt T, Lowden A. Morning work: effects of early rising on sleep and alertness. Sleep 1997;20:215-23.

26. Walitt B, Katz RS, Bergman MJ, Wolfe F. Threequarters of persons in the us population reporting a clinical diagnosis of fibromyalgia do not satisfy fibromyalgia criteria: The 2012 National Health Interview Survey. PLoS One 2016;11:e0157235.
27. Häuser W, Sarzi-Puttini P, Fitzcharles MA. Fibromyalgia syndrome: under-, over- and misdiagnosis. Clin Exp Rheumatol 2019;37:90-7.

28. Van Ryckeghem DML, Rost S, Kissi A, Vögele C, Crombez G. Task interference and distraction efficacy in patients with fibromyalgia: an experimental investigation. Pain 2018;159:1119-26.

29. Teodoro T, Edwards MJ, Isaacs JD. A unifying theory for cognitive abnormalities in functional neurological disorders, fibromyalgia and chronic fatigue syndrome: systematic review. J Neurol Neurosurg Psychiatry 2018;89:1308-19.

30. Littlejohn G, Guymer E. Neurogenic inflammation in fibromyalgia. Semin Immunopathol 2018;40:291300 .

31. Oldfield M, MacEachen E, MacNeill M, Kirsh B. 'You want to show you're a valuable employee': A critical discourse analysis of multi-perspective portrayals of employed women with fibromyalgia. Chronic Illn 2018;14:135-53.

32. Collado A, Gomez E, Coscolla R, Sunyol R, Solé E, Rivera J, et al. Work, family and social environment in patients with Fibromyalgia in Spain: an epidemiological study: EPIFFAC study. BMC Health Serv Res 2014;14:513.

33. Wolfe F, Walitt BT, Katz RS, Häuser W. Social security work disability and its predictors in patients with fibromyalgia. Arthritis Care Res (Hoboken) 2014;66:1354-63.

34. Reisine S, Fifield J, Walsh SJ, Feinn R. Do employment and family work affect the health status of women with fibromyalgia? J Rheumatol 2003;30:2045-53. 